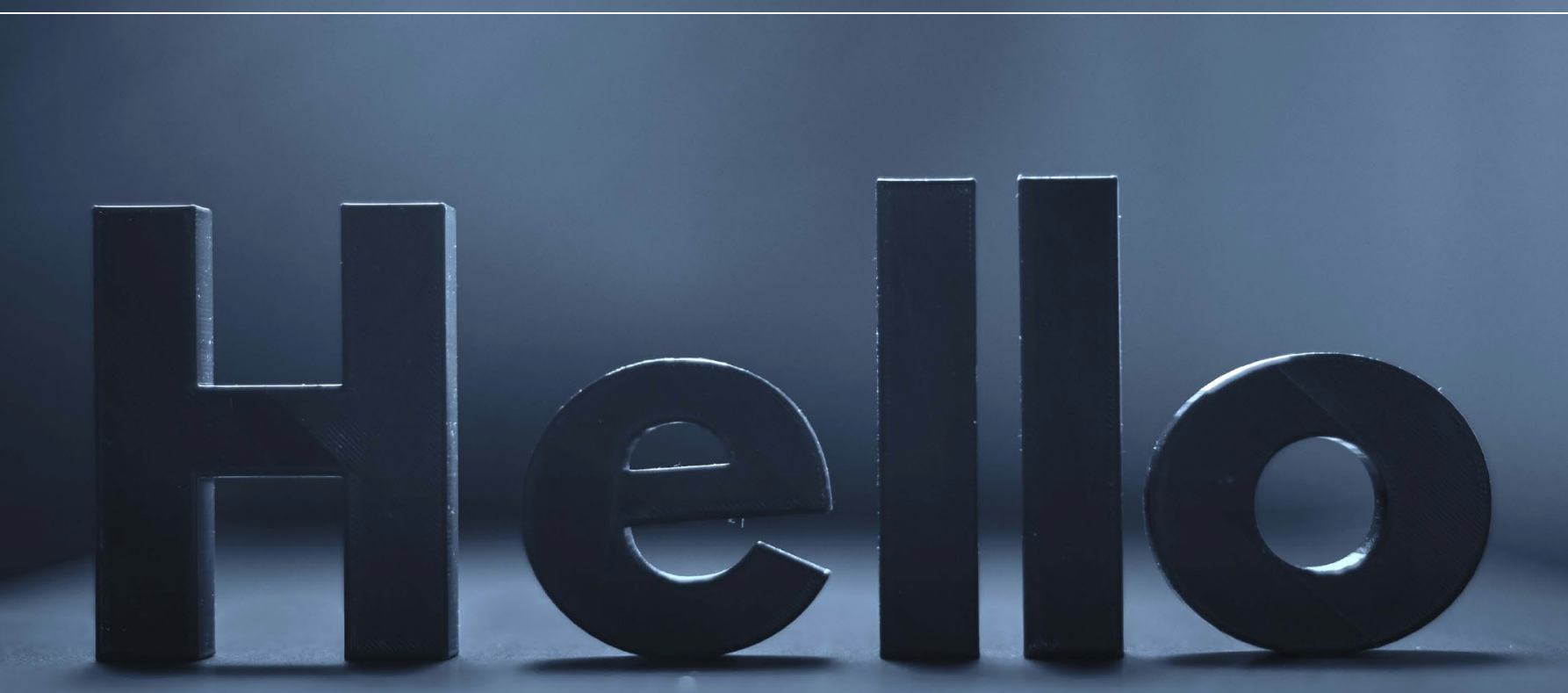

I am delighted to publish Issue 21 of Probation Quarterly. This is my first issue fully in charge as editor and I hope you find the articles in this issue as interesting and relevant to practice as I do. The last few months have been important in the world of probation with a key milestone in the post-TR unification of CRCS and the NPS taking place on 25 June. It seemed to me - looking in from the outside - that this event was accompanied by a full-on awareness raising effort with regional probation directors reporting on Twitter from Unpaid Work sites on the day itself and other media engagements occurring in subsequent weeks. As someone who has long believed that probation deserves more media and public attention this was good to see, although some of the language around introducing chain gangs and probation practitioners as 'crime fighters' seemed rather incongruent with what I see and hear when conducting research in and around the world of probation. That said, it is useful to be reminded of the power that the Probation Service has over the people it subjects to supervision and tweets from the Ministry of Justice served to illustrate that nicely, if unintentionally. These efforts to position probation in the limelight culminated in the first ever celebration of 'probation day' on 21 August, marking the date on which the Probation of Offenders Act was passed in 1907. Probation day events seemed to be more balanced and truer to practitioners' values than the punitivism of those MoJ tweets and I hope we continue to see such portrayals of probation in the future.

On a related note, I have spent some time in the last three months thinking about the use of language in probation, especially when it comes to the way I (i.e. someone without lived experience of systems of punishment) refer to people under supervision. As part of this I have developed a short guide to language that I am asking all PQ contributors to adhere to. You can read the full policy here but, briefly, I am asking writers to use person-centred language as much as possible and to avoid stigmatising words such as 'offender' which does little more than describe what people are rather than describe who they are. I would like to thank David and Jahmaine (members of the Revolving Doors Lived Experience Team) and Philip Mullen (Research Manager at Revolving Doors) for their help with developing this guidance. If you have any thoughts on it, please do get in touch. 
In this issue, Laura Frampton's research on probation practitioners' attitudes towards working with so-called 'paedophile hunters' raises yet more questions about the use of language, a theme which is also relevant to Melanie Jameson and Ian Merrill's articles both of which focus on hidden vulnerabilities such as Specific Learning Disabilities and low literacy levels. The issue also includes an article by Jason Tizedes focusing on his work in the field of technology in corrections, ever important in the context of recovery from the coronavirus (COVID-19) pandemic. Sticking with the pandemic, I am pleased to include an infographic detailing key findings from a joint study by Revolving Doors and the University of Lincoln about experiences of accessing healthcare in the pandemic whilst under probation supervision. Finally, Matt Cracknell and Natalie Rutter outline key findings from their doctoral studies focusing on, respectively, resettlement and bereavement.

This issue also includes a themed section focusing on the process of unification with contributions from policy, practice and academia. Firstly, Jim Barton provides a first-hand account of leading the process and then Sam Ainslie considers what the future holds for different models of probation. Shadae Cazeau explores what unification means for race equality and former practitioners Daniella Nudd and Deena Parma reflect on their experiences of practice and unification. Finally, Jonathan Hussey considers the future of probation through the lens of digital interventions.
Together, these articles suggest that unification is a step in the right direction and that there is considerable potential for improving the way probation services function in England and Wales. However, the jury is still out on exactly whether and how the aspirations in the Target Operating Model, the new commissioning structure, technological developments and a concerted recruitment strategy will result in real benefits for staff in probation and, crucially, people on probation.

The themed section in the next issue will focus on race, racial inequality and the relevance of the BLM movement for probation practice. However, I have struggled to find academic researchers conducting work in this area; a worrying situation considering what we know about the disproportionate impact of the criminal justice system on people from minoritised racial and ethnic groups. So, I would like to finish this introduction with a request for contributions from researchers working in this area, as well as a clarion call to others to do more research focusing on the issue of race in probation.

As ever, I am open to receiving ideas for contributions from academics, policymakers, practitioners and charities - please just get in touch if you have something that you think will be of interest to our readers.

\section{Jake Phillips}

Editor, Probation Quarterly 